\title{
Cigarette smoke increases cardiomyocyte ceramide accumulation and inhibits mitochondrial respiration
}

\author{
Trevor S Tippetts ${ }^{1}$, Duane R Winden ${ }^{1}$, Adam C Swensen², Michael B Nelson', Mikayla O Thatcher ${ }^{1}$, Rex R Saito ${ }^{1}$, \\ Tyler B Condie ${ }^{1}$, Kurtis J Simmons ${ }^{1}$, Allan M Judd ${ }^{1}$, Paul R Reynolds ${ }^{1}$ and Benjamin T Bikman ${ }^{1 *}$
}

\begin{abstract}
Background: Cigarette smoking is a common and lethal worldwide habit, with considerable mortality stemming from its deleterious effects on heart function. While current theories posit altered blood lipids and fibrinogen metabolism as likely mediators, none have explored the role of the sphingolipid ceramide in exacerbating heart function with smoke exposure. Ceramide production is a consequence of cigarette smoke in the lung, and considering ceramide's harmful effects on mitochondrial function, we sought to elucidate the role of ceramide in mediating smoke-induced altered heart mitochondrial respiration.
\end{abstract}

Methods: Lung cells (A549) were exposed to cigarette smoke extract (CSE) and heart cells (H9C2) were exposed to the lung-cell conditioned medium. Adult male mice were exposed sidestream cigarette smoke for 8 wk with dietary intervention and ceramide inhibition. Ceramides and heart cell or myocardial mitochondrial respiration were determined.

Results: Lung cell cultures revealed a robust response to cigarette smoke extract in both production and secretion of ceramides. Heart cells incubated with lung-cell conditioned medium revealed a pronounced inhibition of myocardial mitochondrial respiration, though this effect was mitigated with ceramide inhibition via myriocin. In vivo, heart ceramides increased roughly $600 \%$ in adult mice with long-term sidestream cigarette smoke exposure. This resulted in a significant ceramide-dependent reduction in left myocardial mitochondrial respiration, as heart mitochondria from the mice exposed to both smoke and myriocin injections respired normally.

Conclusions: These results suggest ceramide to be an important mediator of altered myocardial mitochondrial function with cigarette smoke exposure. Thus, anti-ceramide therapies might be considered in the future to protect heart mitochondrial function with smoke exposure.

\section{Background}

Cigarette smoke exposure is the leading cause of preventable deaths worldwide [1] and is among the top ten contributors to the worldwide health burden [2]. Despite concerted social efforts to reduce smoking prevalence, current trends suggest the number of smokers will increase worldwide [3,4]. Moreover, cigarette smoke is a common inhaled toxin-almost half of the U.S. population is regularly exposed to cigarette smoke $[5,6]$ and approximately $20 \%$ of young children live with someone who

\footnotetext{
* Correspondence: benjamin_bikman@byu.edu

'Department of Physiology and Developmental Biology and Chemistry,

Brigham Young University, Provo, UT 84602, USA

Full list of author information is available at the end of the article
}

smokes in the home [7]. Much of smoking's health burden stems from the increased risk of chronic diseases like cancer, emphysema, and cardiovascular disease [8,9], including cardiomyopathy - a deterioration of heart muscle.

Cardiomyocytes are highly oxidative cells with a tremendous reliance on mitochondrial capacity [10], and altered mitochondrial function can lead to heart failure [11-13], a common consequence of cardiomyopathy. Considering the importance of healthy mitochondrial function in cardiomyocyte homeostasis, a valuable area of study is to elucidate the factors that mediate altered heart mitochondrial physiology and its effects with cigarette smoke exposure. Previous studies have observed that cigarette smoke exposure inhibits mitochondrial respiratory 
function in blood cells [14] and myocardium [15], but a mediating mechanism has yet to be identified.

Cigarette smoke has long been known to robustly activate inflammatory pathways in the lung [16], which increases ceramide biosynthesis $[17,18]$. Importantly, ceramides are known to disrupt mitochondrial structure and function $[19,20]$, possibly increasing risk of cardiomyopathy [21]. Thus, the purpose of these studies was to determine whether the sphingolipid ceramide mediates cardiomyocyte mitochondrial disruption with cigarette smoke exposure. Considering the lung's apposition with the environment, the lung is a logical site of external pathogen-induced stress, a product of which is ceramide biosynthesis [17]. Moreover, given the heart's location relative to pulmonary blood flow, the heart is a reasonable site of lung-derived ceramide uptake.

\section{Methods}

\section{Cell culture}

Cigarette smoke extract (CSE) was generated as previously described with slight modifications [22]. Briefly, one 2RF4 research cigarette (University of Kentucky, Lexington, KY) was continuously smoked by connecting the filtered end of the cigarette to a vacuum pump, pulling the particles into $5 \mathrm{ml}$ of DMEM/F12 and the resulting medium was defined as 100\% CSE. The total particulate matter content of 2RF4 cigarettes is $11.7 \mathrm{mg} /$ cigarette, tar is $9.7 \mathrm{mg} /$ cigarette, and nicotine is $0.85 \mathrm{mg} /$ cigarette. Dilutions were made using DMEM/F12 +10\% FBS. Human type II-like pulmonary adenocarcinoma cells (A-549; passage 10-15) were maintained in DMEM/F12 supplemented with 10\% FBS (Invitrogen) and antibiotics. Cells were split into 6 -well dishes and grown to $80 \%$ confluence. $\mathrm{H} 9 \mathrm{C} 2$ cardiomyocytes were maintained in DMEM $+10 \%$ FBS. For differentiation into myotubes, cells were grown to confluency and the medium was replaced with DMEM $+10 \%$ horse serum (Invitrogen, Grand Island, NY). Myotubes were used for experiments on day 3 of differentiation. A-549 cultures were exposed to media supplemented with 10\% CSE or media alone for $4 \mathrm{~h}$, after which the medium was transferred to differentiated H9C2 cardiomyocytes (termed "conditioned medium") for $12 \mathrm{~h}$. Where indicated, cells were treated with myriocin (10 $\mu \mathrm{M}$, Sigma, M1177), a known and widely used inhibitor of ceramide biosynthesis. Muscle cells were harvested for RNA, protein, and lipid isolation following treatments. Cell survival during treatments was confirmed by trypan blue exclusion.

\section{Animals}

Male C57Bl6 mice were housed in a conventional animal house and maintained on a 12-hour light-dark cycle. Two animal studies were conducted. In the first study, animals received standard diet chow (Harlan Teklad
8604) and water ad libitum. At 12 wk of age, animals were randomly divided into room air and cigarette smoke (CS)-exposed groups. Mice were placed in soft restraints and connected to the exposure tower of a nose-only exposure system (InExpose System, Scireq, Canada). Animals were nasally exposed to sidestream CS generated by research cigarettes where a computercontrolled puff was generated every minute, leading to $10 \mathrm{~min}$ of CS exposure followed by $10 \mathrm{~min}$ of fresh air, repeated once. The CS-exposed group inhaled CS from two cigarettes per day for one week, at which point the dosage was increased to two cigarettes twice daily. Control animals were similarly handled and restrained in fresh air for the same duration. For the second study, 12-wk-old mice were separated into one of eight treatment groups for eight weeks. Each of the following groups were duplicated to have one group receive vehicle or myriocin injections $(0.3 \mathrm{mg} / \mathrm{kg})$ every other day for a total of eight groups: 1) control - standard diet chow, no smoke; 2) cigarette smoke exposure (two cigarettes, twice daily) with standard diet chow; 3) high-fat, high-sugar diet (Harlan Teklad 45F30S); 4) high-fat, high-sugar diet with cigarette smoke exposure. Tissues were harvested at the conclusion of the study period. Studies were conducted in accordance with the principles and procedures outlined in the National Institutes of Health Guide for the Care and Use of Laboratory Animals and were approved by the Institutional Animal Care and Use Committee (IACUC) at Brigham Young University.

\section{Lipid analysis}

For isolation of lipids, cell pellets or tissue were suspended in $900 \mu \mathrm{l}$ ice-cold chloroform/methanol (1:2) and incubated for 15 minutes on ice, then briefly vortexed. Separation of aqueous and organic phases required addition of $400 \mu \mathrm{l}$ of ice-cold water and $300 \mu \mathrm{l}$ of ice-cold chloroform. The organic phase was collected into a fresh vial, and lipids were dried in a vacuum centrifuge (Eppendorf Concentrator Plus). Lipids were characterized and quantified using a shotgun lipidomics technique on a Thermo Scientific LTQ Orbitrap XL mass spectrometer. Evaporated lipid samples were re-suspended in a 2:1 chloroform: methanol Folch solution $(200 \mu \mathrm{L})$. The re-suspended lipids were then combined with a modified 2:1:1.25 chloroform: methanol: isopropanol Bligh and Dyer solution $(800 \mu \mathrm{L})$ with $15 \mathrm{mM}$ ammonium acetate acting as an ionizing adduct. A $1.74 \mu \mathrm{M}$ phosphatidylethanolamine, $1 \mu \mathrm{M} \mathrm{C}-17$ ceramide, $1 \mu \mathrm{M}$ tripalmitin internal standard cocktail $(1 \mu \mathrm{L})$ was spiked into each sample for mass calibration and characterization data alignment. Samples were analyzed using a 2.5-minute mass-window scanning method in positive-ion mode at a resolution of 100,000 (FWHM at 
$400 \mathrm{~m} / \mathrm{z}$ ) for all primary $\mathrm{MS}^{1}$ scans. $\mathrm{MS}^{2}$ fragmentation data was also collected (PQD at relative intensity of 35) and manually verified for each mass window to give additional confidence to the correct identification of abundant lipid species. Three technical replicate mass spectrometer runs were performed on each sample. Samples were injected at $8 \mu \mathrm{L} / \mathrm{min}$ using a direct-inject electrospray ionization (ESI) soft-ionization spray head from a Hamilton GASTIGHT glass syringe. A nitrogen sheath gas spray flow rate of 8 (arb. Units) was used for all runs. The spray voltage and capillary temperature were maintained at $5.0 \mathrm{KV}$ and $275^{\circ} \mathrm{C}$ respectively. Each technical replicate was run in random order to reduce systematic bias. Data were analyzed using in-house developed peak summarization, recalibration, and lipid identification software using lipid database information from the LIPID Metabolites and Pathways Strategy (Lipid MAPS) Lipidomics Gateway database [23]. To ensure highconfidence identifications, an intensity threshold estimated to be $5 \%$ above instrumental static signal was implemented. Lipid identities were only assigned when significantly observable peaks were identified in at least two of the three technical replicate runs. Non-zero lipid quantities were averaged from the replicate runs. The lipid species identified across different ionization states or with adducts were totaled together. Quantification was completed by normalizing total ion counts to the relative abundance of the internal standard that was spiked into each sample.

\section{Cell and myocardium permeabilization}

For cells, $\mathrm{H} 9 \mathrm{C} 2$ cardiomyocytes were detached in culture dishes with $0.05 \%$ trypsin-EDTA (Sigma) and growth medium was added to the culture. Contents were transferred to a tube and centrifuged for $10 \mathrm{~min}$ at $1000 \times \mathrm{g}$ at RT. After removal of supernatant, cells were lifted in MiR05 [0.5 mM EGTA, $3 \mathrm{mM} \mathrm{MgCl}_{2}, 60 \mathrm{mM} \mathrm{K}-$

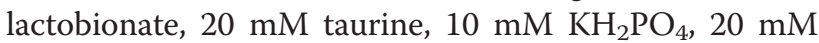
HEPES, $110 \mathrm{mM}$ sucrose, and g/l BSA (Sigma; A3803) adjusted to $\mathrm{pH} 7.1$ ] plus $1 \mathrm{mg} / \mathrm{ml}$ digitonin and gently rocked at RT for $5 \mathrm{~min}$ before centrifugation at $1000 \times g$ for $5 \mathrm{~min}$. After discarding supernatant, cells were then suspended in $2.2 \mathrm{ml}$ warm MiR05 and transferred to chambers in the O2K (Oroboros Instruments, Innsbruck, Austria). Following respiration protocol (outlined below), cells were removed from the chambers and used for further analysis, including protein quantification. For myocardial mitochondrial respiration, left ventricle was
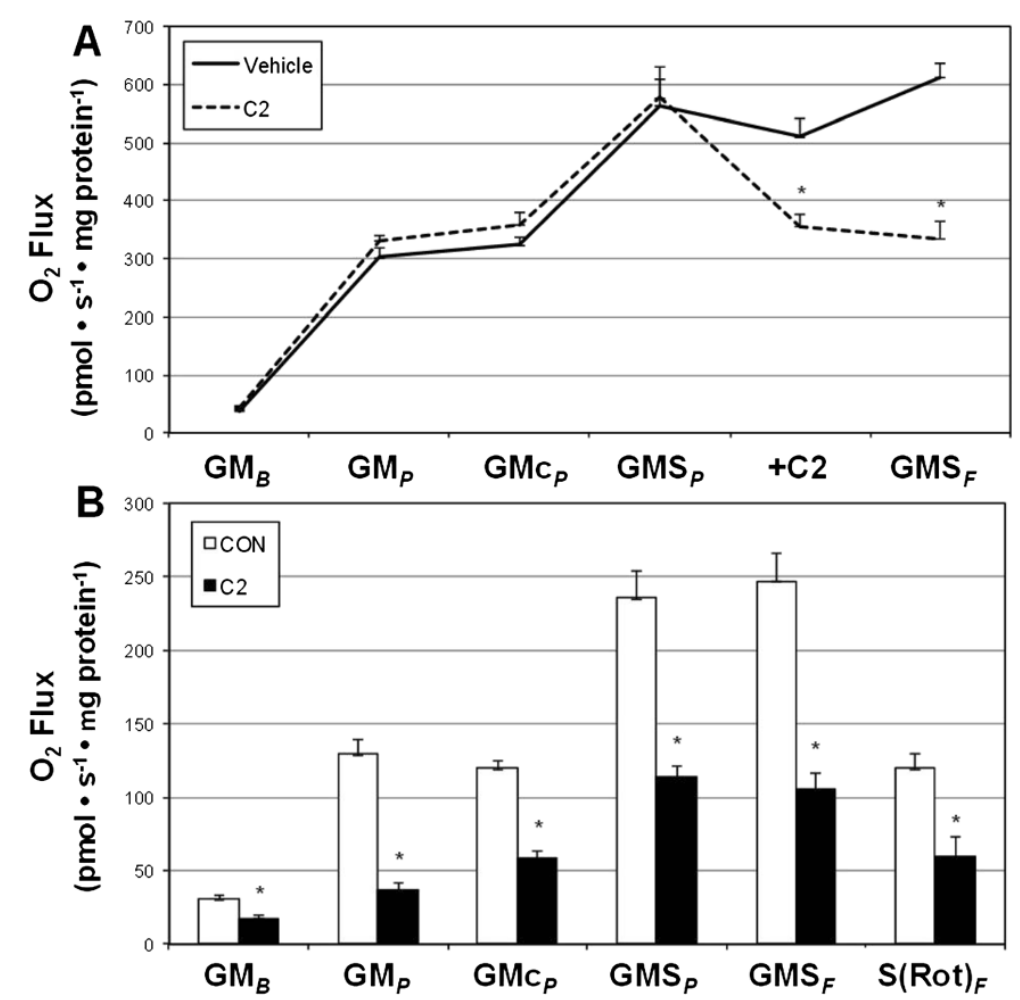

Figure 1 Ceramide inhibits left ventricle mitochondrial respiration. $A$ : Respiration rates of mitochondria isolated from left ventricle myocardium with addition of $\mathrm{C2}$-ceramide during respiration protocol $(20 \mu \mathrm{M} ; n=4)$. B: Mitochondrial respiration from permeabilized left ventricle myocardium (30 min) with continuous incubation with C2-ceramide $(20 \mu \mathrm{M} ; \mathrm{n}=8)$. See Methods for more details on respiration protocol. * $P<0.05$. 
quickly removed from euthanized mice and immediately placed in ice-cold buffer X $(60 \mathrm{mM} \mathrm{K-MES}$, $35 \mathrm{mM} \mathrm{KCl}, 7.23 \mathrm{mM} \mathrm{K}{ }_{2}$ EGTA, $2.77 \mathrm{mM} \mathrm{CaK}{ }_{2}$ EGTA, $20 \mathrm{mM}$ imidazole, $20 \mathrm{mM}$ tuarine, $5.7 \mathrm{mM}$ ATP, $15 \mathrm{mM}$ PCr, $6.56 \mathrm{mM} \mathrm{MgCl}_{2}-6 \mathrm{H}_{2} \mathrm{O}, \mathrm{pH}$ 7.1) and trimmed of connective tissue. Small fiber bundles were prepared and gently separated along their longitudinal axis under a surgical scope (Olympus, ST) to 1-2 mg. Bundles were then transferred to a tube with chilled buffer $\mathrm{X}$ and $50 \mu \mathrm{g} / \mathrm{ml}$ saponin and rocked at $4^{\circ} \mathrm{C}$ for $30 \mathrm{~min}$, then washed in buffer $\mathrm{Z}(105 \mathrm{mM}$ K-MES, $30 \mathrm{mM} \mathrm{KCl}, 10 \mathrm{mM} \mathrm{KH} \mathrm{PO}_{4}, 5 \mathrm{mM} \mathrm{MgCl}-6 \mathrm{H}_{2} \mathrm{O}$, $0.5 \mathrm{mg} / \mathrm{ml} \mathrm{BSA}, \mathrm{pH} 7.1)$ at $4^{\circ} \mathrm{C}$ for at least $15 \mathrm{~min}$. Samples were then blotted dry and weighed.

\section{Mitochondrial isolation}

To isolate mitochondria from left ventricle myocardium, the whole heart was placed in isolation buffer (300 mM sucrose, $10 \mathrm{mM}$ Na-HEPES, $0.2 \mathrm{mM}$ EDTA, $\mathrm{pH}$ 7.2) and the left ventricle isolated. After finely mincing the sample, trypsin (Sigma T9935) was added for two minutes before adding trypsin inhibitor (Sigma
T9003). The sample was then transferred to a conical tube and allowed to settle. After removal of supernatant, samples were resuspended in isolation buffer with BSA (Sigma A3803) and homogenized with Teflon pestle before centrifugation $\left(600 \times g\right.$ for $10 \mathrm{~min}$ at $\left.4^{\circ} \mathrm{C}\right)$. Supernatant was then transferred to a new tube and centrifuged $\left(8000 \times g\right.$ for $15 \mathrm{~min}$ at $\left.4^{\circ} \mathrm{C}\right)$, then washed by gently adding isolation buffer and rotating the tube. A portion of this suspension is used for protein quantification. The pellet was then resuspended with isolation buffer + BSA.

\section{Mitochondrial respiration protocol}

High-resolution $\mathrm{O}_{2}$ consumption was determined at $37^{\circ} \mathrm{C}$ in permeabilized cells and fiber bundles using the Oroboros O2K Oxygraph with MiR05 respiration buffer. Before addition of sample into respiration chambers, a baseline respiration rate was determined. After addition of sample, the chambers were hyperoxygenated to $\sim 350 \mathrm{nmol} / \mathrm{ml}$. Following this, respiration was determined by all or parts of the following substrate-uncoupler-inhibitor-titration (SUIT) protocol [24]: electron flow through complex I was supported by
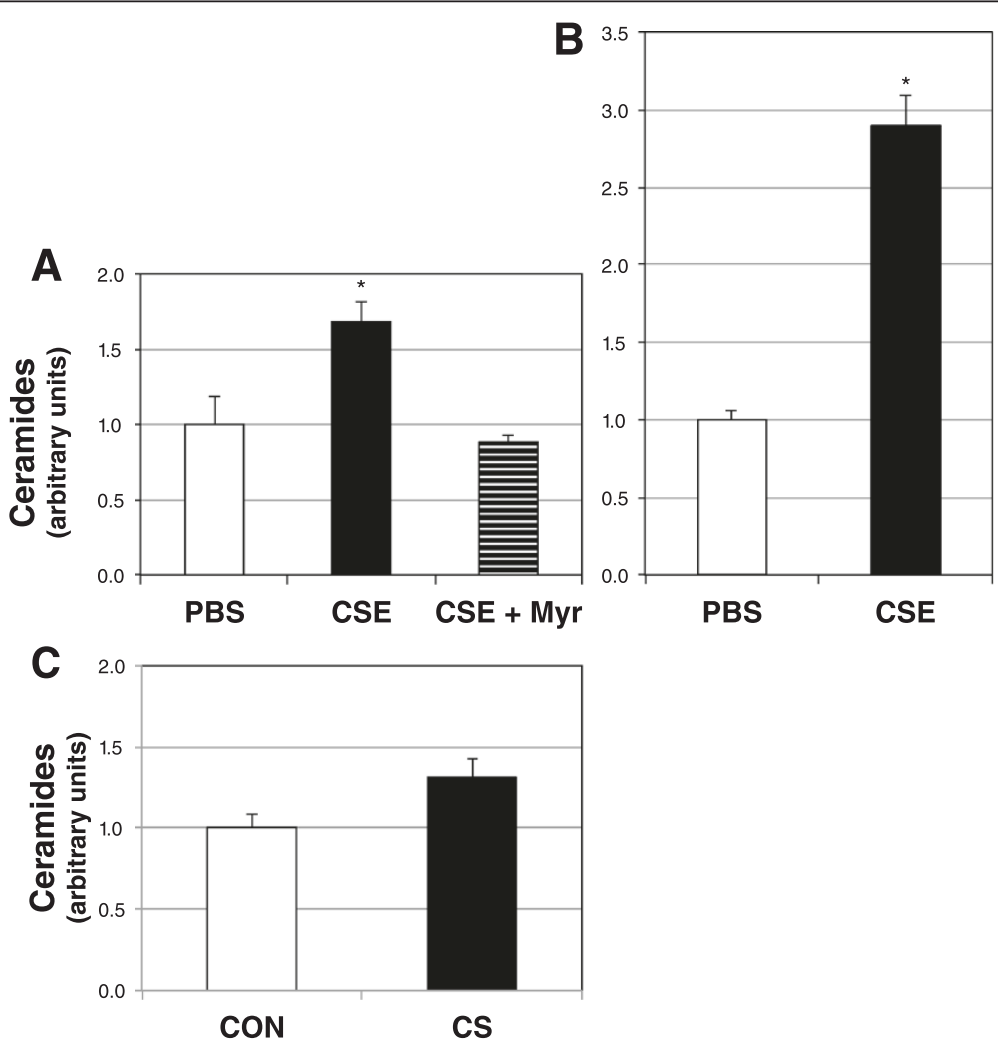

Figure $\mathbf{2}$ Lung cells make and secrete ceramide in response to cigarette smoke extract. A: Ceramide levels in A549 cells treated with PBS- or 10\% cigarette smoke extract-containing medium without (CSE) or CSE with myriocin (CSE + Myr), a ceramide inhibitor, for $12 \mathrm{~h}$ $(n=6)$. B: Ceramides in culture medium of A549 cells following a 12-h treatment with PBS or CSE $(n=6)$. C. Ceramides were determined from whole blood of adult mice following $5 \mathrm{~d}$ of room air (CON) or sidestream cigarette smoke (CS) $(P=0.069 ; n=5)$. ${ }^{*}<<0.05$ for $C S E$ vs. PBS. 
glutamate + malate (10 and $2 \mathrm{mM}$, respectively) to determine basal oxygen consumption $\left(\mathrm{GM}_{B}\right)$. Following stabilization, ADP $(2.5 \mathrm{mM})$ was added to determine oxidative phosphorylation capacity $\left(\mathrm{GM}_{P}\right)$. Succinate was added $\left(\mathrm{GMS}_{P}\right)$ for complex I + II electron flow into the Q-junction. To determine full electron transport system (F) capacity over oxidative phosphorylation, the chemical uncoupler carbonyl cyanide 4-(trifluoromethoxy) phenylhydrazone (FCCP) was added $(0.05 \mu \mathrm{M}$, followed by $0.025 \mu \mathrm{M}$ steps until maximal $\mathrm{O}_{2}$ flux was reached). Complex II-supported ETS was then measured by inhibiting complex I with rotenone (Rot; $0.5 \mu \mathrm{M})$. Mitochondrial membrane integrity was tested in all experiments by adding cytochrome $c(10 \mu \mathrm{M}$; $\mathrm{GMc}_{P}$ ). Lastly, residual oxygen consumption was measured by adding antimycin A $(2.5 \mu \mathrm{M})$ to block complex III action, effectively stopping any electron flow, which provides a baseline rate of respiration. Where indicated, C2-ceramide (Sigma A7191; $20 \mu \mathrm{M}$ ) was added to respiration chambers.

\section{Statistics}

Data are presented as the mean \pm SEM. Data were compared by ANOVA with Tukey's post-hoc analysis (Graphpad Prism; La Jolla, CA). Significance was set at $p<0.05$.

\section{Results}

Ceramide inhibits cardiomyocyte mitochondrial respiration To determine the effects of ceramide on cardiac mitochondrial respiration, we utilized two models. First, mitochondria were isolated from left ventricle myocardium. During the course of the respiration protocol in the isolated mitochondria, C2-ceramide was added to one oxygraph chamber. The addition of ceramide $(+\mathrm{C} 2)$ elicited a rapid and significant reduction in mitochondrial respiration that was sustained through maximal respiration
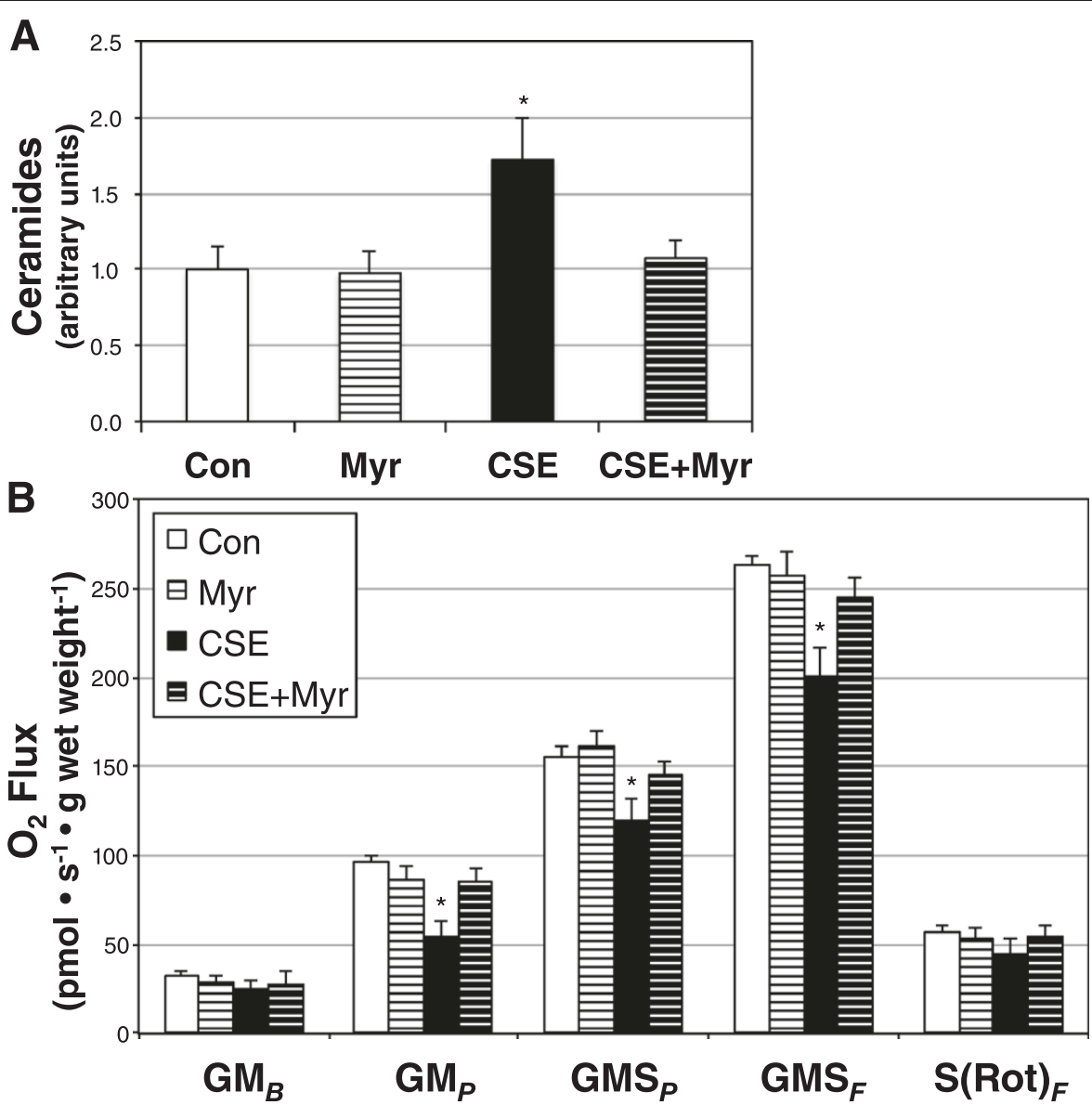

Figure 3 Ceramide is necessary for decreased mitochondrial respiration in myocardial cells following treatment with conditioned medium from CSE-treated lung cells. A: Ceramide levels in H9C2 cardiomyocytes treated with conditioned medium from A549 alveolar type 2 cells following incubation with normal growth medium (Con), Con with myriocin (Myr), cigarette smoke extract (CSE), and CSE with Myr (CSE + Myr) $(n=4)$. B: Mitochondrial respiration from H9C2 cardiomyocytes following treatment in identical conditions $(n=5)$. See Methods for more details on respiration protocol. ${ }^{*} P<0.05$ for CSE vs. Con. 
with FCCP (Figure 1A; see Methods for protocol details). A second model was the use of permeabilized intact left ventricle myocardium. One sample was incubated with C2ceramide throughout the length of the protocol, which elicited a sustained reduction in mitochondrial respiration throughout the entire protocol (Figure 1B).

\section{Cigarette smoke extract increases lung cell ceramide production and secretion}

The deleterious effect of cigarette smoking on heart function is undeniable, but the mechanism communicating the pulmonary insult to the heart is not clear. As proof of concept that the lung is capable of producing and secreting ceramides with smoke exposure, we treated A549 alveolar type 2 cells with cigarette smoke extract (CSE). Relative to PBS treatment, ceramides increased over $60 \%$ in CSE-treated lung cells, though this effect was mitigated with myriocin co-treatment (Figure 2A). Further, CSE treatment elicited an almost three-fold increase in ceramide secretion into medium compared with PBS treatment (Figure 2B). We also observed an upward trend $(P=0.069)$ in circulating ceramides from whole blood following $5 \mathrm{~d}$ of sidestream smoke exposure in adult mice (Figure $2 \mathrm{C}$ ).

\section{Ceramide is necessary for smoke extract-induced altered cardiomyocyte mitochondrial disruption}

To determine the effects of lung cell-secreted ceramides on heart cell function, we utilized a conditioned medium in vitro model. Briefly, following incubation with PBSor CSE-containing medium, with or without myriocin co-treatment, the conditioned medium from lung cells was transferred to $\mathrm{H} 9 \mathrm{C} 2$ cardiomyotubes for $12 \mathrm{~h}$. Following the incubation with conditioned medium, we determined cardiomyotube ceramide accrual and mitochondrial respiration. Ceramides were significantly increased in cardiomyotubes treated with conditioned medium from CSE-treated lung cells (Figure 3A). However, when lung cells received treatment with myriocin in addition to CSE, the conditioned medium had no effect on heart cell ceramides (Figure 3A). Mitochondrial respiration in the heart cells followed a similar trend as ceramides. Namely, respiration in heart cells receiving CSE conditioned medium was negatively affected, but
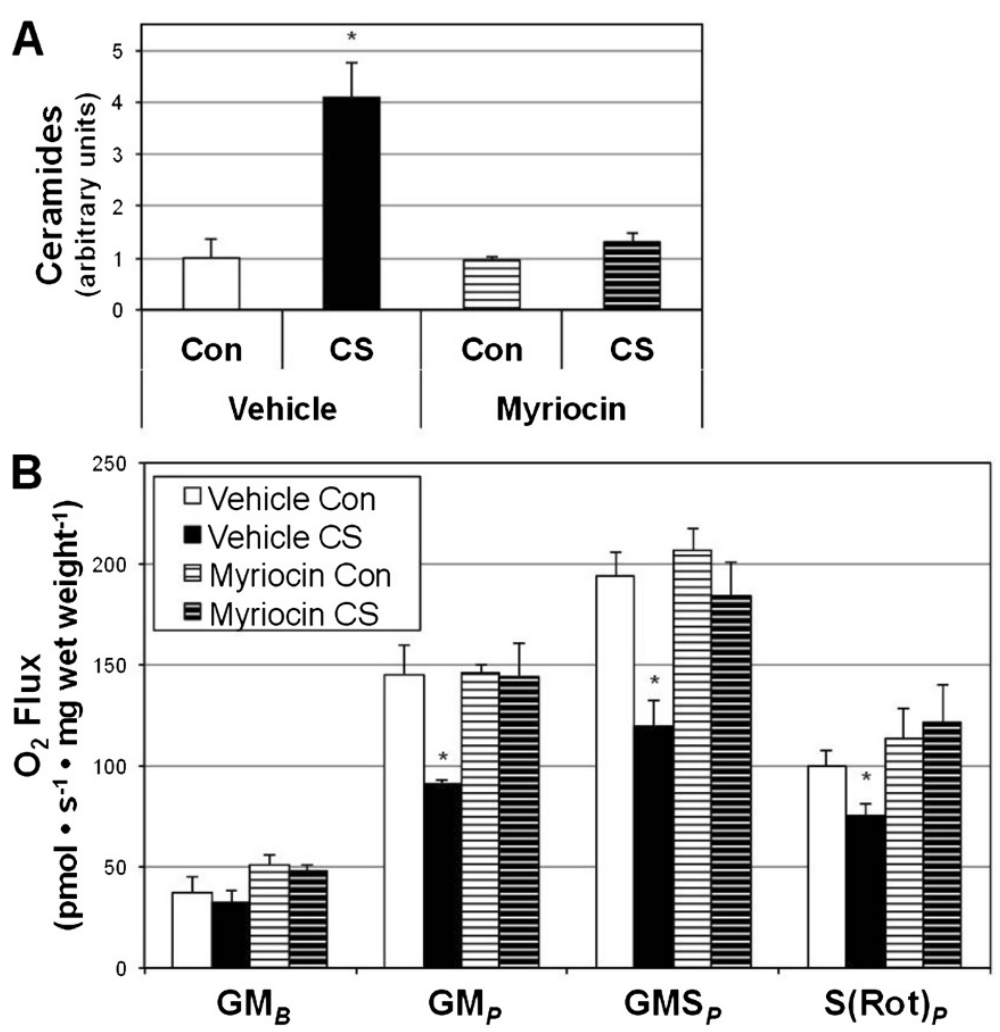

Figure 4 Myriocin prevents left ventricle ceramide accrual and mitochondrial dysfunction with cigarette smoke. Mice were exposed to room air (Con) or cigarette smoke (CS) for 1 wk while receiving PBS (vehicle) or myriocin injections every other day. $\boldsymbol{A}$ : Ceramides were measured from left ventricle following treatment period $(n=6)$. $\boldsymbol{B}$ : Mitochondrial respiration was reduced with $C S$ treatment in vehicle-injected animals $(\mathrm{n}=6) .{ }^{*} P<0.05$ for CS vs all other treatments. 
not when myriocin was included in the lung cell culture medium (Figure 3B).

\section{Ceramide inhibition prevents reduced myocardial mitochondrial respiration with cigarette smoke}

To more accurately determine the role of ceramides in mediating smoke-induced decayed heart mitochondrial respiration, we exposed animals to CS for 1 wk while receiving injections of PBS (vehicle) or myriocin every other day. Left ventricle ceramides increased four fold with CS compared with room air-exposed mice (Figure 4A) with vehicle injections, though myriocin prevented this effect. Moreover, respiration was protected from CS in myriocin-injected animals (Figure 4B).

Given the evidence suggesting the role of diet in increasing heart complications [25] and ceramide accrual [26], we provided a high-fat, high-sugar (Western diet; WD) to animals in conjunction with smoke (or room air) exposure over the course of an 8-wk study. Similar to before, animals received vehicle (PBS) or myriocin injections every other day. In addition to observing a roughly 6 -fold increase in heart ceramides with smoke exposure, we found an equally great increase in heart ceramides in animals receiving WD diet and smoke (Figure 5A). However, ceramide inhibition was only partially successful in the WD + CS group. In general, ceramide accrual was associated with reduced myocardial mitochondrial respiration (Figure 5B).

\section{Discussion}

Previous research demonstrated that smoke exposure contributes to cardiomyopathy $[27,28]$, which can be a consequence of altered mitochondrial function [21], and we have recently shown that sidestream smoke alters mitochondrial function in skeletal muscle [29]. Considering current worldwide smoking trends [3,4], cardiomyopathy and other cardiovascular burdens mediated by cigarette smoke are likely to increase. To date, the main instigators thought to mediate the heart-specific effects of smoking are altered blood lipids and changes in fibrinogen metabolism, [30,31], though the actual impact of these mechanisms is unknown [30]. While ceramides are known to mediate cellular disruption in the lung with smoking [32], its impact on cardiomyocyte function with smoking has not been adequately explored. Thus, the purpose of this project was to determine the role of
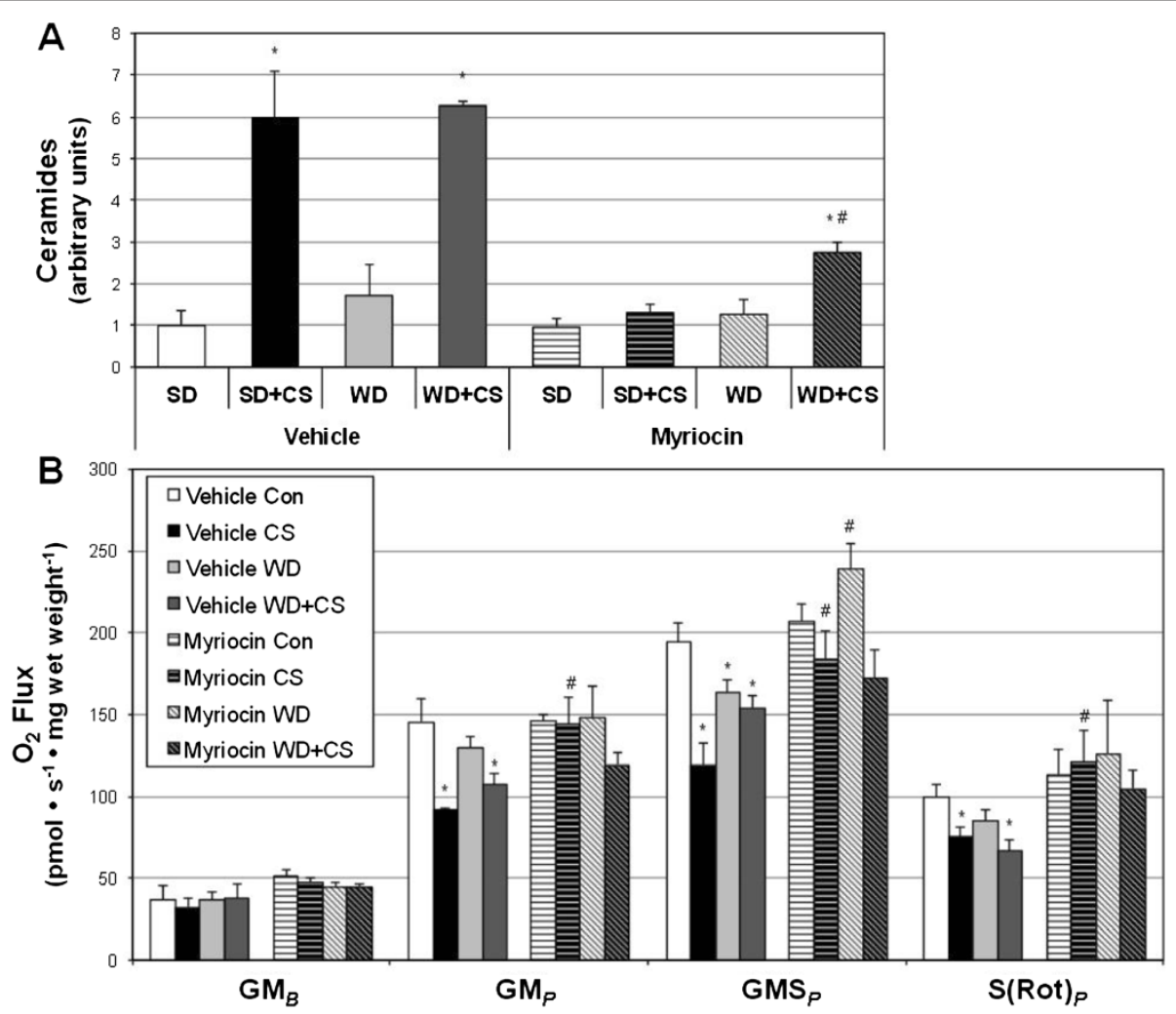

Figure $\mathbf{5}$ Western diet exerts a minimal effect on heart ceramides in smoke-exposed mice. Mice were exposed to room air (Con) or cigarette smoke (CS) for 8 wk while receiving PBS (vehicle) or myriocin injections every other day. Mice also received either a standard diet (SD) or Western diet (WD). $\boldsymbol{A}$ : Ceramides were measured from left ventricle following treatment period $(n=4)$. $\boldsymbol{B}$ : Mitochondrial respiration was determined from permeabilized left ventricle myocardium $(n=8)$. ${ }^{*} P<0.05$ for treatment vs. Vehicle SD. \#P<0.05 for WD +CS myriocin vs. WD + CS vehicle. 
tobacco smoke-induced ceramides in disrupting cardiomyocyte mitochondrial function. Our major discoveries were that lung cells secrete ceramide with sidestream smoke exposure and that ceramide accumulates in heart tissue and alters mitochondrial function.

To our knowledge, the first study to explore the effects of ceramide on mitochondrial respiration was published by the Hoppel laboratory, where they observed a rapid and robust inhibition of respiration in isolated heart mitochondria upon ceramide treatment [20], and subsequent work corroborates these findings [33]. We confirm those observations by Gudz et al. [20] in isolated heart mitochondria and report similar findings in permeabilized left ventricle. Additionally, we have previously shown that ceramides substantially inhibit complex II action and that the general adverse effect of ceramides on mitochondrial respiration is dependent on ceramide-induced mitochondrial fission [24]. Similarly, our findings of ceramide accrual in the lung with smoking corroborate those from other laboratories [34-36], but while previous work focused on ceramide generation via sphingomyelinase, our effective use of myriocin suggests the importance of de novo ceramide synthesis in sidestream smoke-induced ceramide accumulation. However, while myriocin injections were sufficient to completely block ceramide accrual with smoking or diet separately, it was insufficient to prevent an increase in ceramides with combined smoking and diet. This may be a result of insufficient myriocin action in the midst of an overpowering stimulus (diet and smoke combined), or that sphingomyelinase may be particularly relevant in our combined treatment.

Importantly, we not only find increased ceramide production in lung cells with smoke exposure, but also ceramide release, providing proof of concept that the lung may be at least a source of systemic ceramide accrual with smoke exposure. This is supported by our finding of an upward trend in circulating ceramides with smoke exposure. Nonetheless, ongoing experiments are testing the hypothesis that secreted ceramide by smoke-exposed pulmonary tissues travel and accumulate in cardiac muscle. Related to this, our conclusions that ceramide is the relevant component within the cultured medium upon transfer of medium from lung cells to cardiomyocytes is based on our use of myriocin. However, due to the harmful cocktail of molecules within the CSE, it is possible that a non-ceramide variable exists.

The level of ceramide accumulation we observe in the heart with smoking is substantial. We have previously quantified ceramide in various tissues (i.e., skeletal muscle, liver, brain) with dietary intervention $[17,24,37]$ and rarely observed greater than a roughly twofold increase in ceramides; similar changes have been observed in the heart [26]. However, cigarette smoking appears to be a more robust inducer of systemic ceramide accumulation compared with diet. We found a roughly four-fold increase in heart ceramides after only 1 wk of smoke exposure (Figure 4) that increased to a six-fold change with an 8-wk exposure (Figure 4A). Interestingly, supplementing the smoking regimen with a dietary component (Western diet, Harlan Teklad 45F30S) had no additive effect on heart ceramides (Figure 5A).

\section{Conclusions}

In conjunction with our recent findings of altered skeletal muscle function with cigarette smoke exposure [29], the results of these studies implicate ceramide as an important mediator of myriad systemic metabolic effects. In particular, we find evidence that ceramides are a mediator of sidestream smoke-induced altered heart mitochondrial function. While interventions to promote smoking cessation should continue, the increase in worldwide smoking and cardiovascular complications highlights the need for immediate therapies. Our findings suggest that ceramide inhibition may be a novel and potentially valuable therapeutic modality to protect heart function for those who are unwilling or unable to vacate smoke environments.

\section{Competing interests}

The authors declare that they have no competing interests.

\section{Authors' contributions}

TST, MBN, MOT, RRS, TBC, KJS conducted cell culture studies. TST, DRW, MBN, MOT, RRS, TBC, KJS performed animal studies. TST, ACS, MOT isolated and quantified ceramides. TST, BTB performed mitochondrial assays. PRR provided technical expertise with sidestream cigarette smoke studies. AMJ, BTB conceived of the study. BTB prepared the manuscript. All authors read and approved the final manuscript.

\section{Author details}

'Department of Physiology and Developmental Biology and Chemistry, Brigham Young University, Provo, UT 84602, USA. ${ }^{2}$ Department of Chemistry and Biochemistry, Brigham Young University, Provo, UT 84602, USA.

Received: 6 October 2014 Accepted: 17 November 2014

Published: 22 November 2014

\section{References}

1. WHO urges more countries to require large, graphic health warnings on tobacco packaging: the WHO report on the global tobacco epidemic, 2011 examines anti-tobacco mass-media campaigns. Cent Eur J Public Health 2011, 19:133-151.

2. Deitel $\mathrm{M}$ : Overweight and obesity worldwide now estimated to involve 1.7 billion people. Obes Surg 2003, 13:329-330.

3. $\mathrm{Ng} \mathrm{M}$, Freeman MK, Fleming TD, Robinson M, Dwyer-Lindgren L, Thomson B, Wollum A, Sanman E, Wulf S, Lopez AD, Murray CJL, Gakidou E: Smoking prevalence and cigarette consumption in 187 countries, 1980-2012. JAMA 2014, 311:183-192

4. Results from the 2010 National Survey on Drug Use and Health: Summary of National Findings. Substance Abuse and Mental Health Services Administration 2011.

5. Pirkle JL, Flegal KM, Bernert JT, Brody DJ, Etzel RA, Maurer KR: Exposure of the US population to environmental tobacco smoke: the Third National Health and Nutrition Examination Survey, 1988 to 1991. JAMA 1996, 275:1233-1240. 
6. Pirkle JL, Bernert JT, Caudill SP, Sosnoff CS, Pechacek TF: Trends in the exposure of nonsmokers in the U.S. population to secondhand smoke: 1988-2002. Environ Health Perspect 2006, 114:853-858.

7. Vital signs: nonsmokers' exposure to secondhand smoke - United States, 1999-2008. MMWR Morb Mortal Wkly Rep 2010, 59:1141-1146.

8. Smoking-attributable mortality, years of potential life lost, and productivity losses-United States, 2000-2004. MMWR Morb Mortal Wkly Rep 2008, 57:1226-1228.

9. Lakier JB: Smoking and cardiovascular disease. Am J Med 1992, 93:8S-12S.

10. Lopaschuk GD, Jaswal JS: Energy metabolic phenotype of the cardiomyocyte during development, differentiation, and postnatal maturation. J Cardiovasc Pharmacol 2010, 56:130-140.

11. Winter SC, Buist NR: Cardiomyopathy in childhood, mitochondrial dysfunction, and the role of L-carnitine. Am Heart J 2000, 139:S63-69.

12. Holmgren D, Wahlander H, Eriksson BO, Oldfors A, Holme E, Tulinius M: Cardiomyopathy in children with mitochondrial disease; clinical course and cardiological findings. Eur Heart J 2003, 24:280-288.

13. Lesnefsky EJ, Moghaddas S, Tandler B, Kerner J, Hoppel CL: Mitochondrial dysfunction in cardiac disease: ischemia-reperfusion, aging, and heart failure. J Mol Cell Cardiol 2001, 33:1065-1089.

14. Miro O, Alonso JR, Jarreta D, Casademont J, Urbano-Marquez A, Cardellach F: Smoking disturbs mitochondrial respiratory chain function and enhances lipid peroxidation on human circulating lymphocytes. Carcinogenesis 1999, 20:1331-1336.

15. Knight-Lozano CA, Young CG, Burow DL, Hu ZY, Uyeminami D, Pinkerton KE, Ischiropoulos $H$, Ballinger SW: Cigarette smoke exposure and hypercholesterolemia increase mitochondrial damage in cardiovascular tissues. Circulation 2002, 105:849-854.

16. Reynolds PR, Schmitt RE, Kasteler SD, Sturrock A, Sanders K, Bierhaus A, Nawroth PP, Paine R 3rd, Hoidal JR: Receptors for advanced glycation end-products targeting protect against hyperoxia-induced lung injury in mice. Am J Respir Cell Mol Biol 2010, 42:545-551.

17. Holland WL, Bikman BT, Wang LP, Yuguang G, Sargent KM, Bulchand S, Knotts TA, Shui G, Clegg DJ, Wenk MR, Pagliassotti MJ, Scherer PE, Summers SA: Lipid-induced insulin resistance mediated by the proinflammatory receptor TLR4 requires saturated fatty acid-induced ceramide biosynthesis in mice. J Clin Invest 2011, 121:1858-1870.

18. Bikman BT: A role for sphingolipids in the pathophysiology of o besity-induced inflammation. CMLS 2012, 69:2135-2146.

19. Bikman BT, Summers SA: Ceramides as modulators of cellular and whole-body metabolism. J Clin Invest 2011, 121:4222-4230.

20. Gudz TI, Tserng KY, Hoppel CL: Direct inhibition of mitochondrial respiratory chain complex III by cell-permeable ceramide. J Biol Chem 1997, 272:24154-24158.

21. Marin-Garcia J, Goldenthal MJ, Pierpont ME, Ananthakrishnan R: Impaired mitochondrial function in idiopathic dilated cardiomyopathy: biochemical and molecular analysis. J Card Fail 1995, 1:285-291.

22. Reynolds PR, Cosio MG, Hoidal JR: Cigarette smoke-induced Egr-1 upregulates proinflammatory cytokines in pulmonary epithelial cells. Am J Respir Cell Mol Biol 2006, 35:314-319.

23. Fahy E, Subramaniam S, Murphy RC, Nishijima M, Raetz CR, Shimizu T, Spener F, van Meer G, Wakelam MJ, Dennis EA: Update of the LIPID MAPS comprehensive classification system for lipids. J Lipid Res 2009, 50(Suppl):S9-14.

24. Smith ME, Tippetts TS, Brassfield ES, Tucker BJ, Ockey A, Swensen AC, Anthonymuthu TS, Washburn TD, Kane DA, Prince JT, Bikman BT: Mitochondrial fission mediates ceramide-induced metabolic disruption in skeletal muscle. Biochem J 2013, 456:427-439.

25. Wilson CR, Tran MK, Salazar KL, Young ME, Taegtmeyer H: Western diet, but not high fat diet, causes derangements of fatty acid metabolism and contractile dysfunction in the heart of Wistar rats. Biochem J 2007, 406:457-467.

26. Baranowski M, Blachnio A, Zabielski P, Gorski J: PPARalpha agonist induces the accumulation of ceramide in the heart of rats fed high-fat diet. J Physiol Pharmacol 2007, 58:57-72.

27. Gvozdjakova A, Bada V, Sany L, Kucharska J, Kruty F, Bozek P, Trstansky L, Gvozdjak J: Smoke cardiomyopathy: disturbance of oxidative processes in myocardial mitochondria. Cardiovasc Res 1984, 18:229-232.

28. Lough J: Cardiomyopathy produced by cigarette smoke. Ultrastructural observations in guinea pigs. Arch Pathol Lab Med 1978, 102:377-380.
29. Thatcher MO, Tippetts TS, Nelson MB, Swensen AC, Winden DR, Hansen ME, Anderson MC, Johnson IE, Porter JP, Prince JT, Reynolds PR, Bikman BT: Ceramides mediate cigarette smoke-induced metabolic disruption in mice. Am J Physiol Endocrinol Metab 2014

30. Cullen P, Schulte H, Assmann G: Smoking, lipoproteins and coronary heart disease risk. Data from the Munster Heart Study (PROCAM). Eur Heart J 1998, 19:1632-1641.

31. Newby DE, Wright RA, Labinjoh C, Ludlam CA, Fox KA, Boon NA, Webb DJ: Endothelial dysfunction, impaired endogenous fibrinolysis, and cigarette smoking: a mechanism for arterial thrombosis and myocardial infarction. Circulation 1999, 99:1411-1415.

32. Petrache I, Natarajan V, Zhen L, Medler TR, Richter AT, Cho C, Hubbard WC, Berdyshev EV, Tuder RM: Ceramide upregulation causes pulmonary cell apoptosis and emphysema-like disease in mice. Nat Med 2005, 11:491-498.

33. Novgorodov SA, Gudz TI: Ceramide and mitochondria in ischemia/ reperfusion. J Cardiovasc Pharmacol 2009, 53:198-208.

34. Schweitzer KS, Hatoum H, Brown MB, Gupta M, Justice MJ, Beteck B, Van Demark M, Gu Y, Presson RG Jr, Hubbard WC, Petrache I: Mechanisms of lung endothelial barrier disruption induced by cigarette smoke: role of oxidative stress and ceramides. Am J Physiol Lung Cell Mol Physiol 2011, 301:L836-846

35. Filosto S, Castillo S, Danielson A, Franzi L, Khan E, Kenyon N, Last J, Pinkerton K, Tuder R, Goldkorn T: Neutral sphingomyelinase 2: a novel target in cigarette smoke-induced apoptosis and lung injury. Am J Respir Cell Mol Biol 2011, 44:350-360.

36. Levy M, Khan E, Careaga M, Goldkorn T: Neutral sphingomyelinase 2 is activated by cigarette smoke to augment ceramide-induced apoptosis in lung cell death. Am J Physiol Lung Cell Mol Physiol 2009, 297:L125-133.

37. Bikman BT, Guan Y, Shui G, Siddique MM, Holland WL, Kim JY, Fabrias G, Wenk MR, Summers SA: Fenretinide prevents lipid-induced insulin resistance by blocking ceramide biosynthesis. J Biol Chem 2012, 287:17426-17437.

doi:10.1186/1471-2261-14-165

Cite this article as: Tippetts et al:: Cigarette smoke increases cardiomyocyte ceramide accumulation and inhibits mitochondrial respiration. BMC Cardiovascular Disorders 2014 14:165.

\section{Submit your next manuscript to BioMed Central and take full advantage of:}

- Convenient online submission

- Thorough peer review

- No space constraints or color figure charges

- Immediate publication on acceptance

- Inclusion in PubMed, CAS, Scopus and Google Scholar

- Research which is freely available for redistribution 